\title{
Genetics of Vesicoureteral Reflux
}

\author{
F. Nino ${ }^{\mathrm{a}}$, M. Ilari ${ }^{\mathrm{a}}$, C. Noviello ${ }^{\mathrm{a}}$, L. Santoro ${ }^{\mathrm{b}}$, I.M. Rätsch ${ }^{\mathrm{b}}$, A. Martino ${ }^{\mathrm{a}}$ and G. Cobellis ${ }^{\mathrm{a}, *}$
}

${ }^{a}$ Pediatric Surgery Unit - Salesi Children's Hospital - Università Politecnica delle Marche - Ancona, Italy; ${ }^{b}$ Clinics of Pediatrics - Pediatric Nephrology Unit - Salesi Children's Hospital - Università Politecnica delle Marche - Ancona, Italy

\begin{abstract}
Vesicoureteral reflux (VUR) is the retrograde passage of urine from the bladder to the upper urinary tract. It is the most common congenital urological anomaly affecting $1-2 \%$ of children and $30-40 \%$ of patients with urinary tract infections. VUR is a major risk factor for pyelonephritic scarring and chronic renal failure in children. It is the result of a shortened intravesical ureter with an enlarged or malpositioned ureteric orifice. An ectopic embryonal ureteric budding development is implicated in the pathogenesis of VUR, which is a complex genetic developmental disorder. Many genes are in-

G. Cobellis volved in the ureteric budding formation and subsequently in the urinary tract and kidney development. Previous studies demonstrate an heterogeneous genetic pattern of VUR. In fact no single major locus or gene for primary VUR has been identified. It is likely that different forms of VUR with different genetic determinantes are present. Moreover genetic studies of syndromes with associated VUR have revealed several possible candidate genes involved in the pathogenesis of VUR and related urinary tract malformations. Mutations in genes essential for urinary tract morphogenesis are linked to numerous congenital syndromes, and in most of those VUR is a feature. The Authors provide an overview of the developmental processes leading to the VUR. The different genes and signaling pathways controlling the embryonal urinary tract development are analyzed. A better understanding of VUR genetic bases could improve the management of this condition in children.
\end{abstract}

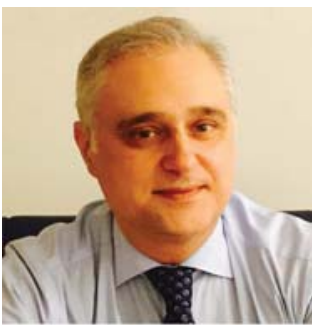

Keywords: Genetic association, Genetic linkage, Prune belly syndrome, Ureteric bud, Uretero-vesical junction, Vesicoureteral reflux.

\section{INTRODUCTION}

Vesicoureteral reflux (VUR) is the retrograde flow of urine from the bladder into the upper urinary tract and it is the most common urological anomaly in children.

Primary VUR is a congenital condition caused by the abnormal development and malfunction of the ureterovesical junction (UVJ). By contrast, secondary VUR is an acquired condition due to an increased intravesical pressure resulting as a secondary effect, in anatomical or neurological bladder outflow obstruction [1].

Primary VUR occurs in $1-2 \%$ of the pediatric population and in $30-40 \%$ of children presenting urinary tract infections (UTI s) [1-5].

The widespread use of prenatal ultrasound, has highlighted that $3-19 \%$ of infants with hydronephrosis on antenatal ultrasound scan screening could be affected by VUR, but its real prevalence remains uncertain because early diagnosis requires invasive radiology and most VUR spontaneously resolves $[2,6]$.

The ureter and bladder physiology plays a pivotal role in the genesis of VUR.

\footnotetext{
*Address correspondence to this author at the Pediatric Surgery Unit-Salesi Children's Hospital-University of Marche, Via Corridoni 11, Ancona, Italy; Tel: +3907136633; Fax: + 3907136281; E-mail: g.cobellis@univpm.it
}

The major function of the ureter is to transport urine from the kidney to the bladder in a unidirectional manner. Therefore, congenital anomalies of the ureter and their associated junction structures (ureteropelvic and ureterovesical) often cause abnormal urine transport, including urinary obstruction and VUR. Both urinary obstruction and VUR increase the pressure in the ureter and renal pelvis and can co-exist in the same patient [7]. Chronic and persistent urinary obstruction or VUR eventually cause hydronephrosis and hydroureter, which may facilitate colonization and growth of bacteria, such as E. Coli in urine, and predispose to recurrent UTI [8].

Congenital reflux nephropathy (RN) could be the result of an abnormal embryological development with subsequent renal dysplasia, and it is largely seen in male infants with high-grade VUR. In addition, periodic exposure to UTIs in patients with VUR can lead to progression of renal parenchymal damage.

Acquired renal scarring associated with VUR could be the result of an acute inflammatory reaction caused by bacterial infection of the renal parenchyma [9] and the risk of renal scarring after an episode of pyelonephritis (proven by dimercaptosuccinic acid [DMSA] scan) is increased in children with high grade VUR, affecting up to $89 \%$ of children with grade IV-V VUR [10].

Reflux nephropathy seems to be an important cause of childhood hypertension and chronic renal failure, despite the improvements in diagnosis and treatment [11]. 
Patients with VUR at a young age may develop reflux nephropathies featuring recurrent UTI, renal scarring, nephron loss, and compensatory hypertrophy of remnant nephrons [12]. Reflux nephropathies ultimately cause proteinuria, degeneration of remnant nephrons, glomerulosclerosis, and tubular atrophy, which could lead to chronic kidney insufficiency and end stage renal disease (ESRD) [13]. It has been reported that about $10 \%$ of patients with reflux nephropathy will progress to chronic kidney insufficiency and ESRD, and eventually they will require dialysis or kidney transplantation [14].

The pathogenesis of reflux nephropathy is not well understood, and it remains unclear why only a subset of patients progress to develop chronic kidney insufficiency and ESRD. The progression from reflux nephropathy to ESRD is often associated with proteinuria [13] and most patients with reflux nephropathy and ESRD have focal segmental glomerulosclerosis (FSGS) [15].

Over the past 30 years, the prevailing hypothesis about the pathogenesis of reflux nephropathy has been that the high pressure from the refluxing urinary stream and recurrent UTI can result in renal injury and kidney parenchyma fibrosis or scarring, also called "acquired" reflux nephropathy. This impairs kidney development and growth $[16,17]$. The pathogenesis of proteinuria and glomerulosclerosis in patients with "acquired" reflux nephropathy and progressive renal insufficiency remains controversial. At least four mechanisms have been proposed, which include immunologic injury, macromolecular trapping and mesangial dysfunction, vascular alterations, and glomerular hypertension. On the other hand, the clinical course resulting in reflux nephropathy and ESRD does not appear to be altered by either surgical correction of VUR or by the control of UTI and hypertension [17]. Some authors hypothesized that children with VUR developed congenital renal scar before birth. It could be caused by the continue progression to "congenital" reflux nephropathy and renal insufficiency, due to abnormal ureteral and kidney development even in the absence of UTI and associated inflammatory reaction in the kidney $[18,19]$.

A familial clustering of VUR has been described with a prevalence of $27-51 \%$ in siblings of patients with VUR [2022 ] and a $66 \%$ rate of VUR in children whose parents had reflux [23].

However VUR can resolve spontaneously, [24] therefore the exact prevalence in family members could be underestimated.

The familial clustering of VUR has been shown to depend on genetic transmission; however there is no agreement on the mode of inheritance. A range of inheritance patterns have been suggested, including autosomal dominant with incomplete penetrance $[25,26]$, autosomal recessive [27] Xlinked [28], and polygenic [29].

Ultimately, an understanding of the genetics of primary VUR remains elusive.

\section{EMBRYOLOGIC DEVELOPMENT OF LOWER URINARY TRACT}

The development of the urinary tract normally begins with the formation of the ureteric bud (UB), which is an outgrowth of the mesonephric duct (Wolfian duct) [29, 30].
Growth of the ureteric bud is stimulated by reciprocal signaling between the bud and the metanephrogenic mesenchyme, resulting in the formation of the ureter and branching to form the collecting ducts [31-33]. This process begins at around 4 weeks of gestation in human (10.5 embryonic days in mouse).

Furthermore, signaling between the bud and the mesenchyme stimulates the metanephrogenic mesenchyme to form the kidney [34, 35]. These developmental processes ultimately leads to a functional kidney that starts to produce urine at about 10 weeks of gestation in human (about 16.5 days in mouse).

At this time the trunk of the ureteric bud elongates without branching to form the ureter, a muscular tube structure that allow the passage of urine from the kidney to the bladder [36]. The elongation of the ureter leads to the ascent of the kidney to its final anatomic position. The morphogenesis of the ureter requires a close interaction between the inner ureteral epithelial cells and the surrounding ureteral mesenchymal cells.

The part of the mesonephric duct between newly developed ureter and urogenital sinus is subsequently removed by apoptosis, [37] where, upon the free end of the developing ureter, inserts into the bladder wall and the vesicoureteric valve is formed. [32, 38, 39].

VUR is caused by the disruption of a proper valvular mechanism at the vesicoureteric junction, which leads to retrograde flow of urine into the ureter or kidney. This is the result of a shortened intravesical ureter, an enlarged or malpositioned ureteric orifice.

It has been shown that abnormalities during embryogenesis, especially a caudally shifted ureteric bud, predispose to ureteric reflux in animal models [40-42].

The key point of this process is the precise position at which the ureteric bud grows out from the mesonephric duct. A range of abnormalities of the kidneys and urinary tract can result from aberrant or multiple budding [30]. Many genes are involved in ureteric budding and subsequent urinary tract and kidney development. Several of these genes could be responsible for isolated VUR, although the precise mutations might differ from those that cause other anomalies.

The morphogenesis of the ureter also requires a close interaction between the inner ureteral epithelial cells and the surrounding ureteral mesenchymal cells. The early simple cuboidal ureteral epithelial cells differentiate into the multilayered urothelium, in response to the molecular signals from the ureteral epithelial and mesenchymal cells. The urothelium is covered by urothelial plaques, that express uroplakin proteins on their surface, and it is impermeable to the caustic effect of urine [43]. In fact, at around 10 weeks in human (16.5 days in mouse), this process coincides with the beginning of urine production by the embryonic kidney.

Meanwhile, the mesenchymal cells differentiate into the stromal cells, smooth muscle cells, and adventitial fibroblasts (also called serosa after maturation). Differentiated smooth muscle cells are further organized into layers with inner circular and outer longitudinal orientation, and are characterized with strong expression of $\alpha$-smooth muscle 
actin $[44,45]$ The ureter smooth muscle differentiation proceed from the distal ureter close to the bladder creating the ureterovesical junction (UVJ) to the proximal ureter that is next to the intrarenal collecting system, creating the ureteropelvic junction (UPJ) [44]. This developmental process is in the opposite direction of the propagation of ureteral peristaltic waves that transport urine from the kidney to the bladder. It initiates in the renal pelvis and then propagates rhythmically, through the ureter wall, to the bladder. Pacemaker cells are located between the calyces region and the UPJ and trigger this contractile activity, producing regular pulsatile electrical signals transmitted along the electrically active smooth muscle cells in the ureter [46].

The bladder and urethra arise from the endodermal urogenital sinus after the urorectal septum partitions of the embryonic cloaca into the ventral urogenital sinus and the dorsal rectum [46]. At around 5 weeks of human gestation (1112 days in mouse), the urogenital sinus is further separated into the anterior vesico-urethral canal and the posterior urogenital sinus. The anterior portion of the urogenital sinus (anterior vesicourethral canal) becomes the bladder, connected to the allantois during early fetal life, through an open outflow tract at its apex called urachus. This outflow tract is only functional at the early embryonic stage to drain the developing bladder to the allantois, through the umbilical cord. By 15 weeks of human gestation, the bladder separates from the umbilicus as the allantois regresses and the residual urachal is further stretched to become the median umbilical ligament. In the meantime, the posterior vesicourethral canal becomes the pelvic portion of urethra in the male (which can be further divided into three segments: pre-prostatic, prostatic, and membranous urethra) and the entire urethra in the female. The posterior portion of the urogenital sinus later develops into the phallic urethra (also called spongy or penile urethra) in the male and the lower portion of the vagina and vaginal vestibule with perineal urethra orifice in the female [47].

At 4.5 weeks of gestation in human (12.5 days in mouse), the posterior part of the Wolffian duct, distal to the ureteric budding site (common nephric duct - CND), shortens, expands and integrates into the urogenital sinus, close to the region where the future bladder neck is located [48, 49]. This leads the ureteric budding site and anterior portion of the Wolffian duct [39]. It has been shown that this is a vitaminA dependent developmental process involving apoptosis of the common nephric duct. This results in the transposition of the ureteric budding site from the Wolffian duct to the urogenital sinus epithelium to allow the formation of the ureteral orifice [50].

After its integration into the future bladder neck region in the urogenital sinus, the CND expands and moves the ureteric orifice anteriorly and separates it from the Wolffian duct.

Subsequent developmental processes of CND apoptosis and expansion of the bladder body displace the ureteric orifices in their final positions in the bladder wall [51] Together with the internal urethral orifice, they form the trigone of the bladder.

At the time that the early bladder is still part of the urogenital sinus, its lumen is covered by bilayered cuboidal cells, rich in glycogen, surrounded by loose undifferentiated mesenchymal cells [52]. The epithelial-mesenchymal interaction is critical for proper bladder development. At about 12 weeks of gestation in human (13.5 days in mouse), bladder mesenchymal cells start to differentiate into smooth muscle cells [52]. At 21 weeks the human fetal bladder has three to five layers of urothelial cells similar to the fully differentiated urothelium, and a well-developed smooth muscle coat consisting of three layers of longitudinal and circular smooth muscles (detrusor) [52].

The function of the human bladder is to store and empty urine. The bladder compliance increases during development as the thickness of the bladder muscle wall increases while the amount of collagen content decreases [53]. The molecular basis of bladder compliance formation and development is largely unknown.

The urinary continence mechanism is guaranteed, in both male and female, by a combination of muscles from the bladder detrusor, trigone, and urethral sphincter complex. The urethral sphincter complex derive from the sphincter urethrae primordium, an embryonic structure of mesenchymal condensation that can be identified in the urogenital sinus at 9 weeks of gestation in human after the division of the cloaca [54]. At about 13-15 weeks of gestation, the "sphincter urethrae primordium" starts to differentiate into two components of urethral sphincter complex that include the inner smooth muscle fibers (lissosphincter) and the outer striated muscle fibers (rhabdosphincter) [54]. After 20 weeks of gestation, both lissosphincter and rhabdosphincter develop into an omega-shaped muscle coat surrounding the urethra with a narrow posterior connective tissue raphe that attaches to the lateral wall of the prostate in the male and the vagina in the female [54]. The smooth muscle lissosphincter also intermixes with the bladder detrusor and is abundant only in the proximal two thirds of the urethra below the bladder neck, whereas the striated muscle rhabdosphincter is located in the distal two thirds of the pelvic urethra [54] The urethral sphincter muscles are innervated by both autonomic nerves (pelvic plexus: regulates the proximal part of the urethra) and somatic nerves (pudendal nerves: control the contraction of the distal part of the urethra) $[55,56]$.

As the bladder muscle mature, it shape a muscle coat around the ureteric orifices in the trigone and functions as an "ureterovesical sphincter" that contracts in response to bladder contraction during voiding and subsequently relaxes following the closure of the external urethral sphincter complex during bladder filling [57].

The contraction of the muscle coat around the ureteric orifices in the trigone acts as an "active" ostial-valve antireflux mechanism to prevent the retrograde urine flow from the bladder back to the ureter and kidney (vesicoureteral reflux) $[58,59]$.

When the ureteric orifice establishes its final position in the bladder trigone, it permits the ureter to enter the bladder muscle laterally in an oblique direction and proceed between the bladder mucosa and detrusor muscle to form an intravesical tunnel structure at the UVJ. The intravesical portion of the ureter collapses during bladder voiding and creates a second anti-reflux mechanism also called the "passive" flap- 
valve mechanism [60]. The active and passive anti-reflux mechanisms works together as a one-way valve allowing ejection of the bolus of urine from the ureter into bladder lumen when its pressure is low during bladder filling, and preventing retrograde flow of urine back to the ureter and kidney when the bladder pressure is high during micturition [57].

\section{GENETIC BASIS OF VESICOURETERAL REFLUX}

Many genes and signaling pathways have been identified to play important roles in early ureteric budding and subsequent ureter development. In the development of the lower urinary tract, many common molecular signaling pathways important in other organ systems play a pivotal role [61]. These include: receptor tyrosine kinase (RTK) (genes Gdnf, Ret) [62]; Wnt (genes: Ctnnb1, Wnt7b, Wnt9b, Fzd1) [63]; Hedgehog (genes Shh. Gli3, Smo, Tshz3) [64]; TGF- $\beta$ (genes: Bmp4, Smad4) [65]; retinoic acid mediated nuclear receptor (genes Rara, Rarb) [50, 66]; renin-angiotensin system(genes: Agt, Ren, Agtr1, Agtr2) [67, 68].

These signaling pathways are fundamental for the normal development of the lower urinary tract, but it has been demonstrated that they are modified by lower urinary tract diseases. such as UTIs that could influence the activity of these signaling pathways $[69,70]$.

We will focus our attention on these molecular signaling pathways, linking them to the phenotype of patients and/or mice with vesicoureteric reflux, when these pathways are disrupted.

Many animal model studies gave new knowledge regarding genes and signaling pathways involved in lower urinary tract development and congenital anomalies.

The best animal model in the field is the mouse because of high similarities between the human and mouse genomes. In addition genetic engineering technologies and large accessible mutant mouse resources provide excellent research tools to characterize the effects of human mutations in vivo.

VUR can be caused by a variety of birth defects affecting the lower urinary tract development. These could interest defects in ureteric budding, ureter differentiation and elongation, peristalsis, UVJ formation, and bladder and urethra development. The location of the ureteric orifice (UVJ) seems to be located laterally and more cephalad in the bladder in patients with primary VUR $[50,71]$. The lateral ectopia of the ureteric orifice may be related to abnormal development of the embryonic ureteric bud, which is also called Machie and Stephens hypothesis or "bud theory" [40]. This is caused by a shortening of the submucosal ureteric segment and a weakening of the flap-valve anti-reflux mechanism. The degree of reflux may correlate with the degree of ureteric orifice laterality and inversely with the length of the intravesical submucosal ureter [72].

The "bud theory" developed by Machie and Stephens [40] proposes that the ureteral orifice derives from the original ureteric budding site on the Wolffian duct during embryonic development. When the ureteric buds arise at abnormal sites of the Wolffian duct, such as multiple ureteric buds, the final sites of the ureteral orifices may also be abnormal, resulting in defective ureterovesical junctions, VUR or UVJ obstruction. They suggest that the final sites of the ureteral orifices in the bladder are determined by the insertion of the common nephric duct into the bladder and its expansion to form the trigone. However, Batourina et al. showed that the common nephric duct does not differentiate into the trigone but instead undergoes apoptosis. Subsequent expansion of the bladder repositions the ureteral orifices to their final positions in the bladder trigone [35]. Moreover formation of multiple ureteric buds may also lead to short duplex ureters, duplex kidneys, ectopic and dysplastic kidneys [35, 73-75].

Therefore, mutations of genes controlling early ureteric buds formation and positioning can cause urinary obstruction, VUR and hydronephrosis during fetal life and after birth in both human and mouse [75-77].

Many syndromes have VUR as one of the phenotypes. Although for some of them the underlying genes have been identified, the genetic basis of primary nonsyndromic VUR remains ill-defined [78].

Family studies show familial clustering of reflux and imply a genetic origin for primary VUR. About $45-50 \%$ percent of children with primary VUR are from families where at least one additional family member is affected [79] The disease often occurs in two or more generations with up to a $65 \%$ transmission rate from parents to children [80] and $34-45 \%$ of an affected patient's siblings will have reflux [81]. Kaefer et al. has showed that $80 \%$ of identical twins and $35 \%$ of fraternal twins develop primary VUR [79] These data strongly support a genetic basis for primary VUR and are consistent with an autosomal dominant mode of inheritance, albeit with incomplete penetrance [80].

Chapman et al. has concluded, through a segregation analysis, that primary VUR is caused by a major dominantly inherited allele [82]. Mutations in PAX2 on chromosome $10 \mathrm{q}$ cause the coloboma-ureteric-renal syndrome (Papillorenal syndrome), in which VUR is part of the phenotype [83] Mutations in PAX2 has been proven to be involved in the pathogenesis of VUR but not in the in the development of other phenotype of CAKUT [84].

Mutations in several other genes have also been identified associated with primary VUR. These include ROBO2 [85, 86] SOX17 [87], UPK3A139, and RET [88]. All these VUR genes have been excluded as major players in primary nonsyndromic VUR [84, 89, 90].

ROBO2 is a member of the immunoglobulin superfamily and encodes a cell adhesion molecule that regulate the outgrowth of the ureteric bud, which is the first step in the development of the metanephric urinary system [91] and its mutations have been identified in patients with VUR from several unrelated families [86]. It is a receptor for the Slit2 ligand and the Slit2-Robo2 signaling acts as a chemorepulsive guidance cue to control axon pathfinding and neuron migration during nervous system development. Slit2-Robo2 signaling seems to play crucial roles in early ureteric buds outgrowth and positioning. It has been shown that a lacking of Slit 2 or ROBO2 in mouse knockouts cause the develop of supernumerary ureteric buds, duplex kidney and hydroureter phenotype [73]. Robo2 is critical for the formation of normal ureteral orifices and for the maintenance of both active and passive anti-reflux mechanisms [76]. Robo2 signaling has 
also been shown to act as a negative regulator on nephrin to influence podocyte foot process architecture in kidney glomeruli [92]. Dobson et al. demonstrate that heterozygous non-synonymous ROBO2 mutations are not sufficient to cause familial vesicoureteric reflux, but could be responsible for VUR in combination with a mutation in another gene [93].

Gdnf encodes a highly conserved secreted protein in the metanephric mesenchyme and induces the ureteral bud outgrowth, during early kidney and ureter development [62], through the receptor tyrosine kinase (RTK) signaling pathway. Its action is mediated by its receptor Ret.

Loss of Gdnf in mice causes absence of ureteric buds formation and renal agenesis [94]. Therefore, mutations in genes associated with the Gdnf/Ret pathway, like Spry1, Gata3, Bmp4, Slit2/Robo2, Foxc1/2, Pax2, Eya1/Six1, and Sall1 cause abnormal ureteric budding phenotypes in mice [95-97].

Mutations in RET have been identified in patients with VUR, ureteral obstruction, megaureter, duplex kidney, renal abnormalities, as well as Hirschsprung's disease [98-100]. Hirschsprung's disease and related disorders have been reported to be associated with congenital anomalies of the kidney and urinary tract (CAKUT), including VUR. Non syndromic Hirschsprung's disease is mainly associated with mutations of the RET proto-oncogene, which encodes the protein receptor tyrosine kinase for GDNF and is located on chromosome 10q [101]. However, a study of 21 patients with Hirschsprung disease and CAKUT investigated by PiniPrato et al. found a mutation in RET in only one patient [98].

Yang et al. have observed a significant association between primary VUR and a G691S polymorphism (rs1799939) in the RET gene [102]. Yu et al. showed that an overexpression of Ret in mice also causes VUR phenotype [103].

BMP4 might have an essential role in nephrogenesis. Dos Reis et al. didn't find correlation between the mutation of BMP4 and VUR. However they found a significant association with other renal disease as multicystic kidney and UPJO [104].

Moreover genetic studies of syndromes with associated VUR have revealed several possible candidate genes involved in the pathogenesis of VUR and related urinary tract malformations (Table 1).

Hypoparathyroidism, sensorineural Deafness, and Renal disease (HDR) have been proven to be connected with a mutations in GATA3 in human, and includes renal dysplasia, unilateral kidney agenesis and VUR phenotypes [105]. The loss of Gata3 leads to ectopic ureteric budding, duplex kidney, hydroureter, as well as vas deferens hyperplasia and uterine agenesis [95]. Gata3 is a transcription factor of the GATA family that is expressed in the ureteric buds. It is regulated by the $\operatorname{Pax} 2$ and $P a x 8$ genes and regulate the Wolffian duct morphogenesis [106]. The majority of cases of HDR syndrome have been mapped to chromosome $10 \mathrm{p}$, particularly mutations of the GATA3 gene, which encodes the trans-acting $\mathrm{T}$ - cell-specific transcription factor GATA-3 protein, and is found at this locus. Up to date the only data regarding HDR syndrome are case reports, so the exact incidence of VUR in HDR syndrome remains unknown.

Table 1. Main Single Gene Mutation associated with Vesicoureteral reflux.

\begin{tabular}{|c|c|c|}
\hline Gene & Phenotype & References \\
\hline \hline GATA3 & $\begin{array}{c}\text { Hypoparathyroidism, Sensorineural Deaf- } \\
\text { ness and Renal disease }\end{array}$ & {$[95,105,106]$} \\
\hline SALL1 & Townes-Brocks Syndrome & {$[107]$} \\
\hline Eya1 & Branchio-Oto Renal Syndrome & {$[54,108]$} \\
\hline Kal1 & Kallman Syndrome & {$[114]$} \\
\hline PAX2 & Renal Colobona syndrome & {$[117,118]$} \\
\hline HOXA13 & Hand-Foot-genital syndrome & {$[118]$} \\
\hline NIPBL & de Lange syndrome & {$[119,120]$} \\
\hline
\end{tabular}
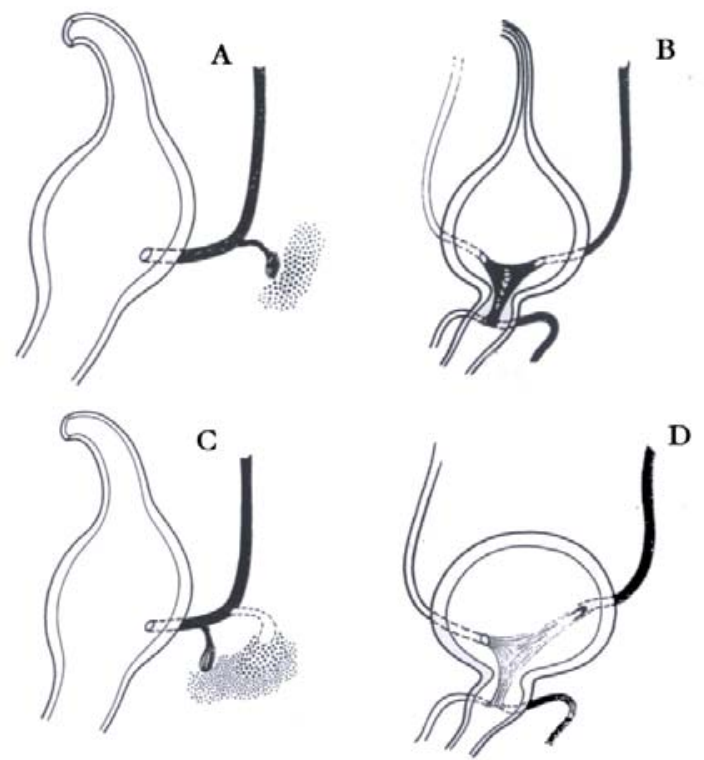

Fig. (1). Embryogenesis of vesicoureteral reflux (VUR) (Modified from: Domini 1998). A; B: Normal development C; D: Abnormal development of vesicoureteral junction leading to VUR.

Townes-Brocks Syndrome (TBS) is a rare complex of malformations, mainly characterized by the triad of imperforate anus, dysplastic ears and thumb malformations. About $30 \%$ of patients present renal impairment, including VUR and end-stage renal disease [107]. This syndrome has been associated with mutations in SALL1, that is a positive regulator of GDNF signaling for ureteric bud formation, expressed in the MM that enhances the canonical Wnt signaling pathway, [107]. SALL1 is the only gene which mutation has been found in association with TBS, and can be identi- 
fied in about $70 \%$ of patients with TBS. Approximately $50 \%$ of TBS cases are due to de novo mutations [107]. Homozygous deletion of Sall1 in mice results in apoptosis of the mesenchyme and renal agenesis but normal blind-ended ureter.

Branchio-oto-renal Syndrome (BOR) is characterized by malformations of the outer, middle and inner ear which are associated with conductive, sensorineural, or mixed hearing impairment, branchial fistulae and cysts, as well as renal malformations. About $5 \%$ of patients with the disorder have VURIt is caused by a mutations in EYA1 (the human homolog of the Drosophila eyes absent gene). BOR syndrome is inherited in an autosomal dominant manner [108] and mutations or deletions of the gene EYA1 have been identified in about $40 \%$ of affected patients. Furthermore, BORassociated mutations of the homeodomain-containing transcription factor SIX5 have been described [54].

Deletions of uroplakins (Upk3a and Upk2) in the urothelium in mice cause loss of superficial umbrella cell layer, overgrowth of the urothelium, urothelial leakage, which lead to hydronephrosis and VUR [43]. Mutations in UPK3A have been found also in patients with VUR, dysplastic kidney and hydronephrosis [109]. The uroplakins strengthen the membrane during bladder filling and emptying, preventing bacterial adherence. They also contribute to the permeability barrier function of the urinary tract [110]. By forming plaques, they strengthen the membrane during bladder filling and emptying, preventing the urothelium from rupturing [111] UPK $3 \mathrm{~A}$ is the only uroplakin with a cytoplasmic domain and Upk3 deletion has been shown to disrupt UPK1B maturation, so that the UPK1A/UPK2 pair can only form abnormally small patches of urothelial plaques, leading to incompetent function of the urothelium and urine leakage [112]. Kelly et al. reported that there is not evidence of linkage or association of markers at the UPK3 locus to VUR [113].

Kallmann syndrome is an hypogonadotrophic hypogonadism, characterized by the association of anosmia and isolated gonadotropin-releasing hormone $(\mathrm{GnRH})$ deficiency. It inheritance has been found as autosomal dominant, autosomal recessive or X-linked. The KAL1 gene, located on the human $\mathrm{X}$-chromosome, is mutated in about $10 \%$ of patients with Kallman syndrome [114] and encodes the protein anosmin-1 (an extracellular- matrix-associated glycoprotein). The frequency of de novo mutations is unknown. Reports suggest that the X-linked recessive form of the disorder is linked with VUR, duplex ureters, duplex kidneys and renal agenesis [114]. FGFR1, PROKR2, PROK2, CHD7 and FGF8 are also associated with Kallman syndrome and, together with KAL1, account for about $25-35 \%$ of cases [110]. The exact incidence of VUR in Kallman syndrome is unknown.

VACTERL syndrome is an association of vertebral, anal, tracheoesophageal, renal and limb defects when at least three organ systems are involved. VUR has been reported in about $40 \%$ of patients with VACTERL [115] Deletions of the distal $13 \mathrm{q}$ chromosome have been described in more than 140 patients with the VACTERL association phenotype [116]. Furthermore, other syndromes caused single gene mutations display VACTERL related malformation patterns including renal malformations. Such syndromes include
Feingold syndrome (also known as oculodigitoesophagoduodenal syndrome), which is caused by mutations in N-MYC, CHARGE syndrome (CHD7), anophthalmiaesophageal-genital syndrome (SOX2), Pallister-Hall syndrome (GLI3), and VACTERL hydrocephalus (FANCB), which is the only X-linked syndrome. Microdeletion within the FOX transcription factor gene cluster at 16q24.1 (FOXF1, MTHFSD, FOXC2 and FOXL1) has been described in patients with VACTERL-related malformations.

Renal coloboma syndrome (RCS) is characterized by hypodysplastic kidneys and optic nerve abnormalities [117]. VUR has been reported in $26 \%$ of patients with RCS [32]. To date, PAX2, the gene encoding the transcription factor PAX2 (10q24.31), is the only gene known to be associated with RCS. Studies have reported that $50 \%$ of individuals with RCS have mutations in PAX2 [117], and three genomic rearrangements of PAX2 have been shown to be linked with $\mathrm{RC}$ [118].

Hand-foot-genital syndrome (HFGS) is characterized by limb malformations and urogenital defects such as VUR. It is inherited in an autosomal dominant manner [118] Mutations in the HOXA13 gene are responsible for the development of HFGS. It encodes the transcription factor homeobox protein HOXA13, [118]. The exact incidence of VUR in the syndrome remains unknown because the only data regarding HFGS are case reports.

de Lange syndrome is characterized by distinctive facial features, growth retardation, hirsutism, and upper limb reduction defects [119] VUR has been reported in $12 \%$ of patients with the disorder [120]. The majority of affected patients have de novo mutations, although de Lange syndrome is inherited in an autosomal dominant or X-linked manner, [119]. The exact mechanisms by which NIPBL contributes to VUR is not known.

Urofacial syndrome (USF, or Ochoa syndrome) is a rare autosomal recessive disorder characterized by a severe and early-onset urinary voiding dysfunction, bowel dysfunction, and a unique inverted facial grimacing expression when patients attempt to smile [121] USF patients often have neurogenic bladder like symptoms such as urinary incontinence, bladder-sphincter dysfunction, UTI, constipation or encopresis. If USF is not diagnosed and treated early, the disease often impairs urine flow causing severe VUR, recurrent UTI, kidney damage, hypertension, and renal failure [121].

Prune Belly Syndrome (PBS) is a rare birth defect affecting about 3.8 per 100,000 live male births [122]. It is characterized by three major defects: hypoplastic or absent abdominal wall musculature, moderate to severe urinary tract dilatation and bilateral undescended testes in males [123]. PBS is an extremely morbid condition, infact about $30 \%$ of the patients die during the initial hospitalization and about $50 \%$ have degrees of urinary pathology during their lifetime, including renal failure in $67 \%$ [123]. The Abdominal wall weakness increases susceptibility to pulmonary infection, decreases physical mobility and causes psychological concerns due to poor cosmesis, that include a partial or complete lack of abdominal muscle with a dry prune like wrinkly skin appearance of the abdomen (so-called prune belly), urinary tract dilatation such as distended thin-walled bladder with 
disorganized detrusor muscle, vesicoureteral reflux, bilateral hydroureter and hydronephrosis, and cryptorchidism [112].

Homozygous loss-of-function mutation of muscarinic acetylcholine receptor M3 (CHRM3) (1q41-q44) seems to be interested in the genesis of PBS [124]. CHRM3 is expressed in bladder urothelial and detrusor muscle cells. Matsui et al. showed that Chrm3 play a key role in bladder detrusor contractions and Chrm3 knockout mice develop distended bladder with thin bladder smooth muscle layer that resembles the bladder phenotype in PBS patients [125].

Also a deletions within $17 \mathrm{q} 12$ that include hepatocyte nuclear factor 1B (HNF1B) have been reported as possible alteration in PBS, and it as been showed in sporadic cases [126], but nowadays is not clear if HNF1B or a disrupted gene is causative, and HNF1B mutations have not yet been implicated in familial PBS.

\section{CONCLUSION}

The genetic basis of VUR is still unclear. In fact a specific causative gene has not been identified. Many genes have been studied, but each of them has been identified only in a small percentage of patients with VUR, also in patients suffering from syndromes in which the VUR is present as a pathological phenotype. Further studies are needed to clarify the appropriate link between the genetic alterations and the development of VUR in certain groups of patients. A better understanding of the genetic bases of VUR could improve the management of this condition in children.

\section{CONFLICT OF INTEREST}

The author(s) confirm that this article content has no conflict of interest.

\section{ACKNOWLEDGEMENTS}

All authors must contributed equally to this work.

\section{REFERENCES}

[1] Cooper, C.S. Diagnosis and management of vesicoureteral reflux in children. Nat. Rev Urol., 2009, 6, 481-489

[2] Puri, P.; Gosemann, J.H.; Darlow, J.; Barton, D.E. Genetics of vesicoureteral reflux. Nat. Rev. Urol., 2011, 8(10), 539-52. doi: 10.1038/nrurol.2011.113.

[3] Cooper, C.S.; Chung, B.I.; Kirsch, A J.; Canning, D.A.; Snyder, H.M.3rd. The outcome of stopping prophylactic antibiotics in older children with vesicoureteral reflux. J. Urol., 2000, 163, 269-273.

[4] Garin, E.H.; Olavarria, F.; Garcia Nieto, V.; Valenciano, B.; Campos, A.; Young, L. Clinical significance of primary vesicoureteral reflux and urinary antibiotic prophylaxis after acute pyelonephritis: a multicenter, randomized, controlled study. Pediatrics, 2006, 117, 626- 632.

[5] Nagler, E.V.T.; Williams, G.; Hodson, E.M.; Craig, J.C. Interventions for primary vesicoureteric reflux. Cochrane Database Syst. Rev., 2011, 6, CD001532. doi:10.1002/14651858.CD 001532.pub4.

[6] Williams, G.; Fletcher J.T.; Alexander S.I.; Craig J.C. Vesicoureteral reflux. J. Am. Soc. Nephol., 2008, 19, 847-862.

[7] Hollowell, J.G.; Altman, H.G.; Snyder, H.M. $3^{\text {rd }}$; Duckett, J.W. Coexisting ureteropelvic junction obstruction and vesicoureteral reflux: diagnostic and therapeutic implications. J. Urol., 1989, 142, 490-493. discussion 501.

[8] Quirino, I.G.; Diniz, J.S.; Bouzada, M.C.; Pereira, A.K.; Lopes, T.J.; Paixao, G.M.; Barros, N.N.; Figueiredo, L.C.; Cabral, A.C.; Simoes e Silva A.C.; Oliveira, E.A. Clinical course of 822 children with prenatally detected nephrouropathies. Clin. J. Am. Soc. Nephrol., 2012, 7, 444-451
Peters, C.; Rushton, H.G. Vesicoureteral reflux associated renal damage: congenital reflux nephropathy and acquired renal scarring J. Urol., 2010, 184, 265-273

[10] Swerkersson, S.; Jodal, U.; Sixt, R.; Stokland, E.; Hansson, S Relationship among vesicoureteral reflux, urinary tract infection and renal damage in children. J. Urol., 2007, 178, 647-651.

[11] Marra, G.; Oppezzo, C.; Ardissino, G.; Daccò, V.; Testa, S.; Avolio, L.; Taioli, E.; Sereni, F.; ItalKid Project. Severe vesicoureteral reflux and chronic renal failure: a condition peculiar to male gender? Data from the ItalKid Project. J. Pediatr., 2004, 144, 677-681.

[12] Bailey, R.R. The relationship of vesico-ureteric reflux to urinary tract infection and chronic pyelonephritis-reflux nephropathy. Clin. Nephrol., 1973, 1, 132-141.

[13] Bailey, R.R.; Lynn, K.L.; Robson, R.A. End-stage reflux nephropathy. Ren. Fail., 1994, 16, 27-35.

[14] Swerkersson, S.; Jodal. U.; Sixt, R.; Stokland, E.; Hansson, S Relationship among vesicoureteral reflux, urinary tract infection and renal damage in children. J. Urol., 2007, 178, 647-651. discussion 650- 641.

[15] Martinell, J.; Lidin-Janson, G.; Jagenburg, R.; Sivertsson, R.; Claesson, I.; Jodal, U. Girls prone to urinary infections followed into adulthood. Indices of renal disease. Pediatr. Nephrol., 1996, 10, 139-142.

[16] Coulthard, M.G.; Keir, M.J. Reflux nephropathy in kidney transplants, demonstrated by dimercaptosuccinic acid scanning. Transplantation, 2006, 82, 205-210.

[17] Toffolo, A.; Ammenti, A.; Montini, G. Long-term clinical consequences of urinary tract infections during childhood: a review. Acta Paediatr., 2012, 101, 1018-1031.

[18] Cendron, M. Reflux nephropathy. J. Pediatr. Urol., 2008, 4, 414421.

[19] Peters, C.; Rushton, H.G. Vesicoureteral reflux associated renal damage: congenital reflux nephropathy and acquired renal scarring. J. Urol., 2010, 184, 265-273.

[20] Giannotti, G.; Menezes, M.; Hunziker, M.; Puri, P. Sibling vesicoureteral reflux in twins. Pediatr. Surg. Int., 2011, 27(5), 513-5.

[21] Parekh, D. J.; Pope, J. C.T.; Adams, M.C.; Brock, J. W. $3^{\text {rd }}$. Outcome of sibling vesicoureteral reflux. J. Urol., 2002, 167, 283-284.

[22] Pirker, M.E.; Colhoun, E.; Puri, P. Renal scarring in familial vesicoureteral reflux: is prevention possible?. J. Urol., 2006, 176 , $1842-1846$

[23] Noe, H.N.; Wyatt, R.J.; Peeden, J.N.Jr; Rivas, M.L. The transmission of vesicoureteral reflux from parent to child. J. Urol., 1992, 148, 1869-1871.

[24] Farhat, W.; McLorie, G.; Geary, D.; Capolicchio, G.; Bägli, D.; Merguerian, P.; Khoury, A. The natural history of neonatal vesicoureteral reflux associated with antenatal hydronephrosis. J. Urol. 2000, 164, 1057-1060.

[25] van Eerde, A.M.; Koeleman, B.P.; van de Kamp, J.M.; de Jong, T.P.; Wijmenga, C.; Giltay, J.C. Linkage study of 14 candidate genes and loci in four large Dutch families with vesico-ureteral reflux. Pediatr. Nephrol., 2007, 22, 1129-1133.

[26] Sanna-Cherchi.; S.; Reese.; A.; Hensle, T.; Caridi, G.; Izzi, C.; Kim, Y.Y.; Konka, A.; Murer, L.; Scolari, F.; Ravazzolo, R.; Ghiggeri, GM.; Gharavi, A.G. Familial vesicoureteral reflux: testing replication of linkage in seven new multigeneration kidnreds. $J$. Am. Soc. Nephrol., 2005, 16(6), 1781-7.

[27] Weng, P.L.; Sanna-Cherchi, S.; Hensle, T.; Shapiro, E.; Werzberger. A.; Caridi, G.; Izzi, C.; Konka, A.; Reese, A.C.; Cheng, R.; Werzberger, S.; Schlussel, R.N.; Burk, R.D.; Lee, J.H.; Ravazzolo, R.; Scolari, F.; Ghiggeri, G.M.; Glassberg, K.; Gharavi, A.G. A recessive gene for primary vesicoureteral reflux maps to chromosome 12p11-q13. J. Am. Soc. Nephrol., 2009, 20, 1633-1640.

[28] Naseri, M.; Ghiggeri, G.M.; Caridi, G.; Abbaszadegan, M R. Five cases of severe vesico-ureteric reflux in a family with an X-linked compatible trait. Pediatr. Nephrol., 2010, 25, 349-352.

[29] de Vargas ,A.; Evans, K.; Ransley, P.; Rosenberg, A.R.; Rothwell, D.; Sherwood, T.; Williams, D.I.; Barratt, T.M.; Carter, C.O. A family study of vesicoureteric reflux. J. Med. Genet., 1978, 15(2), 85-96.

[30] Ichikawa, I.; Kuwajama, F.; Pope, J.C.T.; Stephens, F.D.; Miyazaki, Y. Paradigm shift from classic anatomic theories to contemporary cell biological views of CAKUT. Kidney Int., 2002, 61(3), 889-898.

[31] Murawski, I.J.; Gupta, I.R. Vesicoureteric reflux and renal malformations: a developmental problem. Clin. Genet. 2006, 69, 105-117. 
[32] Murer, L.; Benetti, E.; Artifoni, L. Embryology and genetics of primary vesico-ureteric reflux and associated renal dysplasia. Pediatr. Nephrol., 2007, 22, 788-797.

[33] Reidy, K.J.; Rosenblum, N.D. Cell and molecular biology of kidney development. Semin. Nephrol., 2009, 29, 321-337.

[34] Schedl, A. Renal abnormalities and their developmental origin. Nat. Rev. Genet., 2007, 8, 791-802.

[35] Batourina, E.; Tsai, S.; Lambert, S.; Sprenkle, P.; Viana, R.; Dutta, S.; Hensle, T.; Wang, F.; Niederreither, K.; McMahon, A.P.; Carroll, T.J.; Mendelsohn C.L. Apoptosis induced by vitamin A signaling is crucial for connecting the ureters to the bladder. Nat. Genet., 2005, 37, 1082-1089.

[36] Rosalie H.M.; Lu, W. Lower urinary tract development and disease. Wiley Interdiscip Rev. Syst. Biol. Med., 2013, 5, 307-342.

[37] Batourina, E.; Choi, C.; Paragas, N.; Bello, N.; Hensle, T.; Costantini, F.D.; Schuchardt, A.; Bacallao, R.L.; Mendelsohn, C.L. Distal ureter morphogenesis depends on epithelial cell remodeling mediated by vitamin A and Ret. Nat. Genet., 2002, 32, 109-115

[38] Kelly, H.; Molony, C.M.; Darlow, J.M.; Pirker, M.E.; Yoneda, A.; Green, A.J.; Puri, P.; Barton, D.E. A genome-wide scan for gene involved in primary vesicoureteric reflux. J. Med. Genet., 2007, 44, 710-717.

[39] Vermillion, C.D.; Heale, W. F. Position and configuration of the ureteral orifice and its relationship to renal scarring in adults. $J$. Urol., 1973, 109, 579-584.

[40] Mackie, G.G; Stephens, F.D. Duplex kidneys: a correlation of renal dysplasia with position of the ureteral orifice. J. Urol., 1975, 114, 274-280.

[41] Murawski, I.J.; Gupta, I.R.; Gene discovery and vesicoureteric reflux. Pediatr. Nephrol., 2008, 23, 1021-1027.

[42] Murawski, I.J.; Myburgh, D.B.; Favor, J.; Gupta, I.R. Vesicoureteric reflux and urinary tract development in the Pax2 1Neu+/mouse. Am. J. Physiol. Renal Physiol., 2007, 293(5), F1736-45. Epub 2007 Sep 19

[43] Kong, X.T.; Deng, F.M.; Hu, P.; Liang, F.X.; Zhou, G.; Auerbach, A.B.; Genieser, N.; Nelson, P.K.; Robbins, E.S.; Shapiro, E.; Kachar, B.; Sun, T.T. Roles of uroplakins in plaque formation, umbrella cell enlargement, and urinary tract diseases. J. Cell Biol., 2004, 167, 1195-1204.

[44] Baker, L.A.; Gomez, R.A. Embryonic development of the ureter and bladder: acquisition of smooth muscle. J. Urol., 1998, 160, 545-550.

[45] Yu, J.; Carroll, T.J.; McMahon, A.P. Sonic hedgehog regulates proliferation and differentiation of mesenchymal cells in the mouse metanephric kidney. Development, 2002, 129, 5301-5312.

[46] Lang, R.J.; Tonta, M.A.; Zoltkowski, B.Z.; Meeker, W.F.; Wendt, I.; Parkington, H.C. Pyeloureteric peristalsis: role of atypical smooth muscle cells and interstitial cells of Cajal-like cells as pacemakers. J. Physiol., 2006, 576, 695-705.

[47] Park, J.M. Normal development of the genitourinary tract. In: Wein AJ, editor. Campbell-Walsh Urology. 10th ed. Vol. 4. Philadelphia, PA: Elsevier Saunders; 2012, 2975-3001.

[48] Mackie, G.G.; Awang, H.; Stephens, F.D. The ureteric orifice: the embryologic key to radiologic status of duplex kidneys. J. Pediatr. Surg., 1975, 10, 473-481.

[49] Murawski, I.J.; Gupta, I.R. Vesicoureteric reflux and renal malformations: a developmental problem. Clin. Genet., 2006, 69, 105117 .

[50] Batourina, E.; Tsai, S.; Lambert, S.; Sprenkle, P.; Viana, R.; Dutta, S.; Hensle, T.; Wang, F.; Niederreither, K.; McMahon, A.P.; Carroll, T.J.; Mendelsohn, C.L. Apoptosis induced by vitamin A signaling is crucial for connecting the ureters to the bladder. Nat. Genet., 2005, 37, 1082-1089.

[51] Mendelsohn, C. Using mouse models to understand normal and abnormal urogenital tract development. Organogenesis, 2009, 5, 306-314.

[52] Newman, J.; Antonakopoulos, G.N. The fine structure of the human fetal urinary bladder. Development and maturation. A light, transmission and scanning electron microscopic study. J. Anat., 1989, 166, 135-150.

[53] Kim, K.M.; Kogan, B.A.; Massad, C.A.; Huang, Y.C. Collagen and elastin in the normal fetal bladder. J. Urol., 1991, 146, 524-527.

[54] Sebe, P.; Fritsch. H.; Oswald, J.; Schwentner, C.; Lunacek, A.; Bartsch, G.; Radmayr, C. Fetal development of the female external urinary sphincter complex: an anatomical and histological study. $J$. Urol., 2005, 173, 1738-1742. discussion 1742.
[55] Karam, I.; Droupy, S.; Abd-Alsamad, I.; Korbage, A.; Uhl, J.F.; Benoit, G.; Delmas, V. The precise location and nature of the nerves to the male human urethra: histological and immunohistochemical studies with three-dimensional reconstruction. Eur. Urol., 2005, 48, 858-864.

[56] Karam, I.; Droupy, S.; Abd-Alsamad, I.; Uhl, J.F.; Benoit, G.; Delmas, V. Innervation of the female human urethral sphincter: 3D reconstruction of immunohistochemical studies in the fetus. Eur. Urol., 2005, 47, 627-633. discussion 634.

[57] Shafik, A. Study of the effect of external urethral sphincter contraction on the mechanical activity of the ureterovesical junction and urinary bladder: recognition of the sphinctero-ureterovesical reflex. Urology, 1997, 50, 949-952.

[58] Arena, S.; Fazzari, C.; Arena, F.; Scuderi, M.G.; Romeo, C.; Nicotina, P.A.; Di Benedetto, V. Altered 'active' antireflux mechanism in primary vesico-ureteric reflux: a morphological and manometric study. BJU Int., 2007, 100, 407-412.

[59] Oswald, J.; Brenner, E.; Schwentner, C.; Deibl, M.; Bartsch, G.; Fritsch, H.; Radmayr, C. The intravesical ureter in children with vesicoureteral reflux: a morphological and immunohistochemical characterization. J. Urol., 2003, 170, 2423-2427.

[60] Tanagho, E.A.; Hutch, J.A.; Meyers, F.H.; Rambo, O.N. Jr. Primary Vesicoureteral Reflux: Experimental Studies of Its Etiology. J. Urol., 1965, 93, 165-176.

[61] Dos Santos Junior, A.C.; de Miranda, D.M.; Simões e Silva, A.C. Congenital anomalies of the kidney and urinary tract: an embryogenetic review. Birth Defects Res. C. Embryo. Today, 2014, 102(4), 374-81.

[62] Costantini, F. GDNF/Ret signaling and renal branching morphogenesis: From mesenchymal signals to epithelial cell behaviors. Organogenesis, 2010, 6, 252-262.

[63] Trowe, M.O.; Airik, R.; Weiss, A.C.; Farin, H.F.; Foik, A.B.; Bettenhausen, E.; Schuster-Gossler, K.; Taketo, M.M.; Kispert, A. Canonical Wnt signaling regulates smooth muscle precursor development in the mouse ureter. Development, 2012, 139, 3099-3108.

[64] Cain, J.E.; Islam, E.; Haxho, F.; Blake, J.; Rosenblum, N.D. GLI3 repressor controls functional development of the mouse ureter. $J$. Clin. Invest., 2011, 121, 1199-1206.

[65] Tripathi, P.; Wang, Y.; Casey, A.M.; Chen, F. Absence of canonical Smad signaling in ureteral and bladder mesenchyme causes ureteropelvic junction obstruction. J. Am. Soc. Nephrol., 2012, 23, 618-628.

[66] Kam, R.K.; Deng, Y.; Chen, Y.; Zhao, H. Retinoic acid synthesis and functions in early embryonic development. Cell Biosci., 2012, 2,11 .

[67] Gribouval, O.; Gonzales, M.; Neuhaus, T.; Aziza, J.; Bieth, E.; Laurent, N.; Bouton, J.M.; Feuillet, F.; Makni, S.; Ben Amar, H.; Laube, G.; Delezoide, A.L.; Bouvier, R.; Dijoud, F.; OllagnonRoman, E.; Roume, J.; Joubert, M.; Antignac, C.; Gubler, M.C. Mutations in genes in the renin-angiotensin system are associated with autosomal recessive renal tubular dysgenesis. Nat. Genet., 2005, 37, 964-968.

[68] Yosypiv, I.V. Renin-angiotensin system in ureteric bud branching morphogenesis: insights into the mechanisms. Pediatr. Nephrol., 2011, 26, 1499-1512.

[69] Duell, B.L.; Carey, A.J.; Tan, C.K.; Cui, X.; Webb, R.I.; Totsika, M.; Schembri, M.A.; Derrington, P.; Irving-Rodgers, H.; Brooks, A.J.; Cripps, A.W.; Crowley, M.; Ulett, G.C. Innate transcriptional networks activated in bladder in response to uropathogenic Escherichia coli drive diverse biological pathways and rapid synthesis of IL-10 for defense against bacterial urinary tract infection. J. Immunol., 2012, 188, 781-792.

[70] Tan, C.K.; Carey, A.J.; Cui, X.; Webb, R.I.; Ipe, D.; Crowley, M.; Cripps, A.W.; Benjamin, W.H. Jr.; Ulett, K.B.; Schembri, M.A.; Ulett, G.C. Genome wide mapping of cystitis due to Streptococcus agalactiae and Escherichia coli in mice identifies a unique bladder transcriptome that signifies pathogen-specific antimicrobial defense against urinary tract infection. Infect. Immun., 2012, 80, 31453160 .

[71] Tanagho, E.A.; Guthrie, T.H.; Lyon, R.P. The intravesical ureter in primary reflux. J. Urol., 1969, 101, 824-832.

[72] King, L.R.; Kazmi, S.O.; Belman, A.B. Natural history of vesicoureteral reflux. Outcome of a trial of nonoperative therapy. Urol. Clin. North Am., 1974, 1, 441-455.

[73] Grieshammer, U.; Le, M.; Plump, A.S.; Wang, F., Tessier-Lavigne, M.; Martin, G.R. SLIT2-mediated ROBO2 signaling restricts kid- 
ney induction to a single site. Dev. Cell., 2004, 6, 709-717.

[74] Basson, M.A.; Akbulut, S.; Watson-Johnson, J.; Simon, R.; Carroll, T.J.; Shakya, R.; Gross, I.; Martin, G.R.; Lufkin, T.; McMahon, A.P.; Wilson, P.D.; Costantini, F.D.; Mason, I.J.; Licht, J.D. Sprouty1 is a critical regulator of GDNF/RET-mediated kidney induction. Dev. Cell., 2005, 8, 229-239.

[75] Hains, D.S.; Sims-Lucas, S.; Carpenter, A.; Saha, M.; Murawski, I.; Kish, K., Gupta, I.; McHugh, K., Bates, C.M. High incidence of vesicoureteral reflux in mice with Fgfr2 deletion in kidney mesenchyma. J. Urol., 2010, 183, 2077-2084

[76] Wang, H.; Li, Q.; Liu, J.; Mendelsohn, C.; Salant, D.J.; Lu, W. Non invasive assessment of antenatal hydronephrosis in mice reveals a critical role for Robo2 in maintaining anti-reflux mechanism. PLoS One, 2011, 6, e24763.

[77] Uetani N, Bouchard M. Plumbing in the embryo: developmental defects of the urinary tracts. Clin. Genet., 2009, 75, 307-317.

[78] Murawski, I.J.; Gupta, I.R. Gene discovery and vesicoureteric reflux. Pediatr. Nephrol., 2008, 23, 1021-1027.

[79] Kaefer, M.; Curran, M.; Treves, ST.; Bauer, S.; Hendren, W.H.; Peters, C.A.; Atala, A.; Diamond, D.; Retik, A. Sibling vesicoureteral reflux in multiple gestation births. Pediatrics, 2000, 105, 800804.

[80] Scott, J.E.; Swallow, V.; Coulthard, M.G.; Lambert, H.J.; Lee, R.E. Screening of newborn babies for familial ureteric reflux. Lancet, 1997, 350, 396-400.

[81] Connolly, L.P.; Treves, S.T.; Connolly, S.A.; Zurakowski, D.; Share, J.C.; Bar-Sever, Z.; Mitchell, K.D.; Bauer, S.B. Vesicoureteral reflux in children: incidence and severity in siblings. J. Urol., 1997, 157, 2287-2290.

[82] Chapman, C.J.; Bailey, R.R.; Janus, E.D.; Abbott. G.D.; Lynn, K.L. Vesicoureteric reflux: segregation analysis. Am. J. Med. Genet., 1985, 20, 577-584.

[83] Sanyanusin, P.; Schimmenti, L.A.; McNoe, L.A.; Ward, T.A.; Pierpont, M.E.; Sullivan, M.J.; Dobyns, W.B.; Eccles, M.R. Mutation of the PAX2 gene in a family with optic nerve colobomas, renal anomalies and vesicoureteral reflux. Nat. Genet., 1995, 9, 358364.

[84] Miranda, D.M.; Dos Santos Júnior, A.C.; Dos Reis, G.S.; Freitas, I.S.; Carvalho, T.G.; de Marco, L.A.; Oliveira, E.A.; Simões E Silva, A.C. PAX2 polymorphisms and congenital abnormalities of the kidney and urinary tract in a Brazilian Pediatric Population: Evidence for a role in Vesicoureteral Reflux. Mol. Diagn Ther., 2014, 18(4), 451-7.

[85] van Eerde, A.M.; Duran, K.; van Riel, E.; de Kovel, C.G.; Koeleman, B.P.; Knoers, N.V.; Renkema, K.Y.; van der Horst, H.J.; Bökenkamp, A.; van Hagen, J.M.; van den Berg, L.H.; Wolffenbuttel, K.P.; van den Hoek, J.; Feitz, W.F.; de Jong, T.P.; Giltay, J.C.; Wijmenga, C. Genes in the ureteric budding pathway: association study on vesico-ureteral reflux patients. PLoS One, 2012, 7, e31327.

[86] Bertoli-Avella, A.M.; Conte, M.L.; Punzo, F.; de Graaf, B.M.; Lama, G.; La Manna, A.; Polito, C.; Grassia, C.; Nobili, B.; Rambaldi, P.F.; Oostra, B.A.; Perrotta, S. ROBO2 gene variants are associated with familial vesicoureteral reflux. J. Am. Soc. Nephrol., 2008, 19, 825-831.

[87] Gimelli, S.; Caridi, G.; Beri, S.; McCracken, K.; Bocciardi, R.; Zordan, P.; Dagnino, M.; Fiorio, P.; Murer, L.; Benetti, E.; Zuffardi, O.; Giorda, R.; Wells, J.M.; Gimelli, G.; Ghiggeri, G.M. Mutations in SOX17 are associated with congenital anomalies of the kidney and the urinary tract. Hum. Mutat., 2010, 31, 1352-1359.

[88] Chatterjee, R.; Ramos, E.; Hoffman, M.; VanWinkle, J.; Martin, D.R.; Davis, T.K.; Hoshi, M.; Hmiel, S.P.; Beck, A.; Hruska, K.; Coplen, D.; Liapis, H.; Mitra, R.; Druley, T.; Austin, P.; Jain, S. Traditional and targeted exome sequencing reveals common, rare and novel functional deleterious variants in RET-signaling complex in a cohort of living US patients with urinary tract malformations. Hum. Genet., 2012, 131(11), 1725-38.

[89] Zu, S.; Bartik, Z.; Zhao, S.; Sillen, U.; Nordenskjold, A. Mutations in the ROBO2 and SLIT2 genes are rare causes of familial vesicoureteral reflux. Pediatr. Nephrol., 2009, 24, 1501-1508.

[90] Cordell, H.J.; Darlay, R.; Charoen, P.; Stewart, A.; Gullett, A.M.; Lambert, H.J.; Malcolm, S.; Feather, S.A.; Goodship, T.H.; Woolf, A.S.; Kenda, R.B.; Goodship, J.A.; UK VUR Study Group. Wholegenome linkage and association scan in primary, nonsyndromic vesicoureteric reflux. J. Am. Soc. Nephrol., 2010, 21, 113-123.

[91] Dickson, B.J.; Gilestro, G.F. Regulation of commissural axon path- finding by slit and its Robo receptors. Annu. Rev. Cell Dev. Biol., 2006, 22, 651-675

[92] Fan, X.; Li, Q.; Pisarek-Horowitz, A.; Rasouly, H.M.; Wang, X.; Bonegio, R.G.; Wang, H.; McLaughlin, M.; Mangos, S.; Kalluri, R.; Holzman, L.B.; Drummond, I.A.; Brown, D.; Salant, D.J.; Lu, W. Inhibitory Effects of Robo2 on Nephrin: A Crosstalk between Positive and Negative Signals Regulating Podocyte Structure. Cell Rep., 2012, 2(1), 52-61.

[93] Dobson, M.G.; Darlow J.M.; Hunziker, M.; Green, A.J.; Barton, D.E.; Puri, P. Heterozygous non-synonymous $\mathrm{ROBO} 2$ variants are unlikely to be sufficient to cause familial vesicoureteric reflux. Kidney Int., 2013, 84(2), 327-37.

[94] Sanchez, M.P.; Silos-Santiago, I.; Frisen, J.; He, B.; Lira, S.A.; Barbacid, M. Renal agenesis and the absence of enteric neurons in mice lacking GDNF. Nature, 1996, 382, 70-73.

[95] Grote, D.; Boualia, S.K.; Souabni, A.; Merkel, C.; Chi, X.; Costantini, F.; Carroll, T.; Bouchard, M. Gata3 acts downstream of betacatenin signaling to prevent ectopic metanephric kidney induction. PLoS Genet., 2008, 4, e1000316.

[96] Nie, X.; Xu, J.; El-Hashash, A.; Xu, P.X. Six1 regulates Grem1 expression in the metanephric mesenchyme to initiate branching morphogenesis. Dev. Biol., 2011, 352, 141-151.

[97] Kiefer, S.M.; Robbins, L.; Stumpff, K.M.; Lin, C.; Ma, L.; Rauchman, M. Sall1-dependent signals affect Wnt signaling and ureter tip fate to initiate kidney development. Development, 2010, 137, 30993106.

[98] Pini Prato, A.; Musso, M.; Ceccherini, I.; Mattioli, G.; Giunta, C. Ghiggeri, G.M.; Jasonni, V. Hirschsprung disease and congenital anomalies of the kidney and urinary tract (CAKUT): a novel syndromic association. Medicine (Baltimore), 2009, 88, 83-90.

[99] Jain, S. The many faces of RET dysfunction in kidney. Organogenesis, 2009, 5, 95-108

[100] Takahashi, M. The GDNF/RET signaling pathway and human diseases. Cytokine Growth Factor Rev., 2001, 12, 361-373.

[101] Emison, E.S.; McCallion, A.S.; Kashuk, C.S.; Bush, R.T.; Grice, E.; Lin, S.; Portnoy, M.E.; Cutler, D.J.; Green, E.D.; Chakravarti, A. A common sexdependent mutation in a RET enhancer underlies Hirschsprung disease risk. Nature, 2005, 434(7035), 857-63.

[102] Yang, Y.; Houle, A.M.; Letendre, J.; Richter, A. RET Gly691Ser mutation is associated with primary vesicoureteral reflux in the FrenchCanadian population from Quebec. Hum. Mutat., 2008, 29, 695-702.

[103] Yu, O.H.; Murawski, I.J.; Myburgh, D.B.; Gupta, I.R. Overexpression of RET leads to vesicoureteric reflux in mice. Am. J. Physiol. Renal. Physiol., 2004, 287, 1123-1130.

[104] Reis, G.S.; Simões E Silva, A.C.; Freitas, I.S.; Heilbuth, T.R.; Marco, L.A.; Oliveira, E.A.; Miranda, D.M. Study of the association between the BMP4 gene and congenital anomalies of the kidney and urinary tract. J. Pediatr. (Rio J)., 2014, 90(1), 58-64.

[105] Benetti, E.; Murer, L.; Bordugo, A.; Andreetta, B.; Artifoni, L. 10p12.1 deletion: HDR phenotype without DGS2 features. Exp. Mol. Pathol., 2009, 86, 74-76.

[106] Grote, D.; Souabni, A., Busslinger, M.; Bouchard, M. Pax 2/8regulated Gata 3 expression is necessary for morphogenesis and guidance of the nephric duct in the developing kidney. Development, 2006, 133, 53-61.

[107] Kohlhase, J.; Wischermann, A.; Reichenbach, H.; Froster, U.; Engel, W. Mutations in the SALL1 putative transcription factor gene cause Townes-Brocks syndrome. Nat. Genet., 1998, 18, 81-83.

[108] Chang, E.H.; Menezes, M.; Meyer, N.C.; Cucci, R.A.; Vervoort, V.S.; Schwartz, C.E.; Smith, R.J. Branchio-oto-renal syndrome: the mutation spectrum in EYA1 and its phenotypic consequences. Hum. Mutat., 2004, 23(6), 582-9.

[109] Hoskins, B.E.; Cramer, C.H.; Silvius, D.; Zou, D.; Raymond, R.M.; Orten, D.J.; Kimberling, W.J.; Smith, R.J.; Weil, D.; Petit, C.; Otto, E.A.; Xu, P.X.; Hildebrandt, F. Transcription factor SIX5 is mutated in patients with branchio-oto-renal syndrome. Am. J. Hum. Genet., 2007, 80(4), 800-804.

[110] Jenkins, D.; Bitner-Glindzicz, M.; Malcolm, S.; Hu, C.C.; Allison, J.; Winyard, P.J.; Gullett, A.M.; Thomas, D.F.; Belk, R.A.; Feather, S.A.; Sun, T.T.; Woolf, A.S. De novo Uroplakin IIIa heterozygous mutations cause human renal adysplasia leading to severe kidney failure. J. Am. Soc. Nephrol., 2005, 16, 2141-2149.

[111] Sun, T.T., Liang, F.X.; Wu, X.R. Uroplakins as markers of urothelial differentiation. Adv. Exp. Med. Biol., 1999, 462, 7-18. discussion 103-14. 
[112] Hu, P.; Deng, F.M.; Liang, F.X.; Hu, C.M., Auerbach, A.; Shapiro, E.; Wu, X.R.; Kachar, B.; Sun, T.T. Ablation of uroplakin III gene results in small urothelial plaques, urothelial leakage, and vesicoureteral reflux. Urology, 2001, 57(6 Suppl 1), 117.

[113] Kelly, H.; Ennis, S.; Yoneda, A.; Bermingham, C.; Shields, D.C.; Molony, C.; Green, A.J. Puri, P.; Barton, D.E. Uroplakin III is not a major candidate gene for primary vesicoureteral reflux. Eur. J. Hum. Genet., 2005, 13(4), 500-502.

[114] Duke, V.; Quinton, R.; Gordon, I.; Bouloux, P.M.; Woolf, A.S. Proteinuria, hypertension and chronic renal failure in $\mathrm{X}$-linked Kallmann's syndrome, a defined genetic cause of solitary functioning kidney. Nephrol. Dial. Transplant., 1998, 13(8), 1998-2003.

[115] Kolon, T. F.; Gray, C. L.; Sutherland, R. W.; Roth, D. R.; Gonzales, E.T.Jr. Upper urinary tract manifestations of the VACTERL association. J. Urol., 2000, 163, 1949-1951.

[116] Felix, J. F.; Tibboel, D.; de Klein, A. Chromosomal anomalies in the etiology of oesophageal atresia and tracheo-oesophageal fistula. Eur. J. Med. Genet., 2007, 50, 163-175

[117] Dureau, P.; Attie-Bitach, T., Salomon, R.; Bettembourg, O.; Amiel, J.; Uteza, Y.; Dufier, J.L. Renal coloboma syndrome. Ophthalmology, 2001, 108, 1912-1916.

[118] Bower, M.; Eccles, M.; Heidet, L.; Schimmenti, L.A. Clinical utility gene card for: renal coloboma (Papillorenal) syndrome. Eur. J. Hum. Genet., 2011, 19(9). doi: 10.1038/ejhg.2011.16.

[119] Ramos, F.J.; Puisac, B.; Baquero-Montoya, C.; Gil-Rodríguez, M.C.; Bueno, I.; Deardorff, M.A.; Hennekam, R.C.; Kaiser, F.J.; Krantz, I.D.; Musio, A.; Selicorni, A. FitzPatrick, D.R.; Pié, J. Clinical utility gene card for: Cornelia de Lange syndrome. Eur. J. Hum. Genet., 2015, 23, 1431. doi: 10.1038/ejhg.2014.270 [Epub ahead of print]

[120] Jackson, L.; Kline, A.D.; Barr, M.A.; Koch, S. de Lange syndrome: a clinical review of 310 individuals. Am. J. Med. Genet., 1993 , 47(7), 940-946.

[121] Tu, Y.; Yang, P.; Yang, J.; Xu, Y.; Xiong, F.; Yu, Q.; Gu, W.; Pond, D.; Mendelsohn, N.; Lachmeijer, G.A.; Zhang, S.; Wang,
C.Y. Clinical and genetic characteristics for the Urofacial Syndrome (UFS). Int. J. Clin. Exp. Pathol., 2014, 7(5), 1842-8.

[122] Routh, J.C.; Huang, L.; Retik, A.B.; Nelson, C.P. Contemporary epidemiology and characterization of newborn males with prune belly syndrome. Urology, 2010, 76(1), 44-8.

[123] Granberg, C.F.; Harrison, S.M.; Dajusta, D.; Zhang, S.; Hajarnis, S.; Igarashi, P.; Baker, L.A. Genetic Basis of Prune Belly Syndrome: Screening for HNF1 Gene. J. Urol., 2012, 187(1), 272-278.

[124] Weber, S.; Thiele, H.; Mir, S.; Toliat, M.R.; Sozeri, B.; Reutter, H.; Draaken, M.; Ludwig, M.; Altmüller, J.; Frommolt, P.; Stuart, H.M.; Ranjzad, P.; Hanley, N.A.; Jennings, R.; Newman, W.G.; Wilcox, D.T., Thiel, U.; Schlingmann, K.P.; Beetz, R.; Hoyer, P.F.; Konrad, M.; Schaefer, F.; Nürnberg, P.; Woolf, A.S. Muscarinic Acetylcholine Receptor M3 Mutation Causes Urinary Bladder Disease and a Prune-Belly-like Syndrome. Am. J. Hum. Genet., 2011 89, 668-674.

[125] Matsui, M.; Motomura, D.; Karasawa, H.; Fujikawa, T.; Jiang, J.; Komiya, Y.; Takahashi, S.; Taketo, M.M. multiple functional defects in peripheral autonomic organs in mice lacking muscarinic acetylcholine receptor gene for the M3 subtype. Proc. Natl. Acad Sci. US A, 2000, 97, 9579-9584.

[126] Sanna-Cherchi, S.; Kiryluk, K.; Burgess, K.E.; Bodria, M.; Sampson, M.G.; Hadley, D.; Nees, S.N.; Verbitsky, M.; Perry, B.J.; Sterken, R.; Lozanovski, V.J.; Materna-Kiryluk, A.; Barlassina, C.; Kini, A.; Corbani, V.; Carrea, A.; Somenzi, D.; Murtas, C.; Ristoska-Bojkovska, N.; Izzi, C.; Bianco, B.; Zaniew, M.; Flogelova, H.; Weng, P.L.; Kacak, N.; Giberti, S.; Gigante, M.; Arapovic, A.; Drnasin, K.; Caridi, G.; Curioni, S.; Allegri, F.; Ammenti, A.; Ferretti, S.; Goj, V.; Bernardo, L.; Jobanputra, V.; Chung, W.K.; Lifton, R.P.; Sanders, S.; State, M.; Clark, L.N.; Saraga, M.; Padmanabhan, S.; Dominiczak, A.F.; Foroud, T.; Gesualdo, L.; Gucev, Z.; Allegri, L.; Latos-Bielenska; A.; Cusi, D.; Scolari, F.; Tasic, V.; Hakonarson, H.; Ghiggeri, G.M.; Gharavi, A.G. Copy-number disorders are common cause of congenital kidney malformations. Am. J. Hum. Genet., 2012, 91(6), 987-97. 